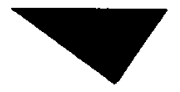

\title{
Sociedade Tecnológica: de Prometeu a Fausto
}

\author{
Maria Cristina Franco Ferraz \\ Universidade Federal Fluminense
}

O notável avanço da pesquisa técnico-científica a partir do término da Segunda Guerra Mundial e, em especial, nas duas últimas décadas, solicita a reflexão filosófica na medida em que parece indicar uma importante ruptura com relação à visão de técnica própria ao pensamento moderno. No âmbito deste trabalho, convocaremos as recentes e instigantes reflexões do sociólogo português Hermínio Martins, que se revelam seminais para um esboço de compreensão, de cunho mais filosófico, de uma das mudanças mais fundamentais, e talvez não tanto analisada, por que passa a sociedade tecnológica contemporânea. Sintetizando e comentando as análises e discussões desse pensador contemporâneo, investigaremos a filosofia da técnica que subjaz aos projetos e pesquisas da tecnociência contemporânea. Tal investigação fornece preciosas indicações para melhor podermos mapear os modos de ser, viver e pensar que tendem a se tornar hegemônicos neste final de milênio, nas sociedades pós-industriais ocidentais.

Em um ensaio publicado originalmente em língua inglesa em 1993'. Hermínio Martins, sociólogo português atualmente fixado na Universidade de Oxford, tematiza a concepção moderna da técnica, e aponta para sua ultrapassagem na contemporaneidade. Partindo de textos inaugurais de filosofia da tecnologia, que remontam a segunda metade do século XIX, sobretudo ao período entre 1860 e 1870, o sociólogo traça as linhas gerais de tal abordagem: a idéia de que os artefatos técnicos seriam extensões, projeções, amplificações do ser humano, do próprio corpo humano. em suas diversas especificações (os sentidos, os membros, o sistema nervoso, etc)." Segundo o autor, a primeira exposição sistemática do que denominou "teoria prostética 
da tecnologia" foi um tratado publicado em 1877 por Ernst Kapp (1808-1896), um hegeliano que, durante um periodo de exílio, se estabeleceu em uma colônia alemã do Texas.

A teoria antropológica da tecnologia elaborada por Kapp tem, como eixo explicativo central, a noção de Organprojektion ("projeção orgânica"): tanto as ferramentas primitivas quanto os instrumentos óticos, acústicos e as invenções recentes por ele testemunhadas são pensadas por analogia a partes do corpo humano, a seu funcionamento tanto motor quanto sensível, e mesmo a suas estruturas internas. Os cabos do telégrafo elétrico são, por exemplo, comparados aos nervos, e as estradas de ferro, ao aparelho circulatório. Como se, com o avanço da técnica, da extensão dos membros do corpo humano, sobretudo da mão, considerada a parte mais tecnogênica do corpo - se passasse a uma projeção das funções internas do corpo, o que requereria um grau de conhecimento científico e de abstração superior. De que maneira tais idéias eram disseminadas na época fica patente quando se lêem os textos de diversas correntes das chamadas vanguardas européias do início do século, ressaltando-se, por sua insistência no tema, Marinetti e todo o futurismo italiano.

Hermínio Martins observa, ainda, que o trabalho de Kapp tem dupla vertente: por um lado, trata-se da primeira formulação mais sistemática de uma teoria antropocêntrica e antropomórfica da tecnologia, em que cada estágio tecnológico é posto em correspondência com uma fase da espécie humana; por outro, de uma teoria tecnológica da antropologia, uma vez que a auto-compreensão da natureza humana só seria alcançada através do estudo dos produtos do trabalho humano, especialmente de suas invenções técnicas. Para Hermínio Martins, essa segunda perspectiva explicaria, inclusive, a importância das metáforas tecnológicas para nossa auto-interpretação, em todas as épocas do pensamento. Tomando a tecnologia como uma força exclusivamente desalientante, Kapp considera que, se a passagem do inconsciente ao consciente é mediada pela externalização técnica, o desenvolvimento da tecnologia implica, necessariamente, o crescimento da auto-consciência humana.

Tal concepção da técnica, a que Hermínio Martins denomina "somatismo tecnológico", devido à ênfase posta no ser humano corporizado, modelo analógico de toda invenção, é radicalmente solapada pela tecnociência contemporânea. As biotecnologias contemporâneas e, de modo geral, o impulso para a mecanizacão da vida orgânica subvertem, fundamentalmente, a prioridade ontológica atribuída, 
no quadro do pensamento moderno, ao ser humano corporizado, ou seja, à prioridade do orgânico sobre o mecânico. Se, para Kapp, os artefatos técnicos eram expressão do inconsciente do homem, para a tecnociência contemporânea não há tal inconsciente, mas apenas sistemas de processamento de informação. O homem é pensado como um sistema complexo de processamento de informação dentre outros. O potencial da tecnologia ultrapassa a estrita referência à condição humana, possibilitando novas criações que apontam para a superação das limitações próprias ao orgânico. As biotecnologias, por exemplo, não buscam apenas aperfeiçoamentos cosméticos ou protéticos para organismos humanos e não-humanos, mas têm como horizonte a criação de novas formas de vida, incluindo, em sua agenda atual, a produção de formas de vida mistas, biológicas e mecânicas, e a criação de computadores orgânicos, por meio de micro-chips biológicos, e não mais feitos de sílica. O sociólogo caracteriza essa nova perspectiva subjacente ao desenvolvimento da tecnociência contemporânea com uma expressão instigante e aparentemente paradoxal, tomada a Victor Ferkiss, em ensaio de 1980": "gnosticismo tecnológico".

Segundo Hermínio Martins, o gnosticismo é comumente identificado ao horror pelo orgânico, a uma verdadeira repugnância pelo corpo e a uma aversão pelo natural, acrescidos de um pathos metafisico, em que uma certa "viscosidade" das coisas é vista como totalmente inimiga do espírito. Ora, uma vez que a tecnologia lida com o mundo material, poderia parecer totalmente avessa a tendências gnosticizantes. Entretanto, algumas esferas da tecnociência contemporânea - da bio-engenharia à inteligência artificial, passando pela clonagem, pelo avanço das tecnologias reprodutivas e da nanotecnologia - se aproximam do gnosticismo na medida em que têm como motor e como uma de suas legitimações a superação dos parâmetros básicos da condição humana: sua finitude, contingência, mortalidade, corporalidade, animalidade, limitação existencial, enfim, a própria condição natural e existencial humana. Desfaz-se, assim, o superficial paradoxo expresso pela noção de "gnosticismo tecnológico", que caracteriza o inesperado cruzamento entre os projetos e aspirações tecnológicos contemporâneos e as utopias gnósticas de se transcender radicalmente a condição humana, e não apenas de a melhorar e de a prover de meios para vencer forças naturais hostis.

Em sua resenha do livro Hegel, Texas na Folha de São Paulo de 19 de Outubro de 97, o sociólogo Laymert Garcia dos Santos associa essas curiosas e surpreendentes articulações entre certa corrente mística e a 
tecnociência contemporânea, ao inquietante suicídio coletivo dos adeptos do Heaven's Gate, especialistas em software que abandonaram seus corpos para embarcar na cauda do cometa Hale-Bopp. Tal gesto talvez expresse esse novo amálgama entre um velho sonho de superação dos limites impostos pela materialidade, pelo orgânico, pelo peso do corpo, e a pesquisa de ponta em informática e 0 avanço das sofisticadas tecnologias do virtual. Com sua exploração filosófica do "gnosticismo tecnológico", Hermínio Martins nos fornece, portanto, uma chave bastante potente para se começar a entender novas e inusitadas formas de misticismo deste final de milênio. Ao mesmo tempo, sua análise perspicaz da afinidade filosófica entre as pesquisas técnico-científicas atuais e velhos sonhos gnósticos possibilita uma reflexão mais ampla sobre as implicações da desmaterialização, da expansão de um plano de realidade produzido pelas novas tecnologias - o virtual. Constituído por velozes fluxos de informação transmitidos em tempo real, através de ondas eletro-magnéticas, tal plano convoca 0 abandono de certas categorizações com as quais nos acostumamos a balizar e operar o pensamento, abalando dicotomias engendradas há mais de dois milênios pela racionalidade ocidental, como, por exemplo, o famoso par essência/aparência. Constitui-se, de fato, um novo plano de realidade que Paul Virilio denominou "trans-aparência"4 . Tais indicações nos incitam à reflexão acerca dos limites dos quadros teóricos tradicionais do pensamento ocidental para se dar conta das alterações engendradas no âmbito da ciência contemporânea e de suas invenções tecnológicas, que sem dúvida marcarão, de modo definitivo, a passagem do milênio.

Partindo da análise de um notável texto do físico socialista J. D. Bernal, publicado em 1929, que antecipa o "gnosticismo tecnológico", Hermínio Martins identifica, na aposta ilimitada na descoberta científica, o impulso para uma "tecnofania", uma vez que, nesta perspectiva do pensamento acerca da tecnologia, a dominação total da natureza tenderia a se desmaterializar em saber absoluto. Com efeito, nos atuais discursos sobre as tecnologias da informação, em que "informação" é o conceito que domina o quadro categorial, o ápice do progresso tecnológico equivaleria à conversão integral do nãoinformacional em informação. Na medida em que a informação na tecnologia eletrônica se transmite à velocidade da luz, o sociólogo ressalta que ressurge, aqui, algo próximo à metafísica neo-platônica da luz. Platão já imbricara de maneira indissolúvel, em sua famosa teoria das idéias, o bem, a divindade, a luz solar, legando, para o pensamento ocidental, a crença de que a perfeição ontológica - que, no caso 
do filósofo grego, se confunde com a perfeição moral - se resolveria, em última instância, em luz. Basta lembrar o famoso mito da caverna, que abre o livro VII da República, contraponto alegórico do diagrama da linha, primeira exposição sistemática, no final do livro VI, da teoria do conhecimento platônica. Segundo Hermínio Martins, vários profetas das tecnologias da informação também prometem tecnofanias, e, mais precisamente, fotofanias. Embora anterior ao laser, aos computadores eletrônicos e à cibernética, o físico socialista Bernal já formulara, em 1929, tal tipo de tecno e fotofania.

a própria consciência pode acabar ou desaparecer em uma humanidade que se tornou completamente eterealizada, tornandose massas de átomos no espaço, comunicando por radiações e, talvez, em última análise, resolvendo-se a si mesma inteiramente em luz.s

Ao apoiar-se na luz, em sua velocidade, as novas tecnologias não apenas possibilitam a desmaterialização como também realizam, de maneira cada vez mais palpável, o fiat lux de antigos sonhos demiúrgicos. Tais reflexões só se tornam possiveis a partir da investigação tanto das práticas e dos discursos da tecnociência contemporânea quanto de sua orientação filosófica, posta em conexão com outras vertentes do pensamento ocidental, revelando, por vezes, curiosas convergências, tal como o "gnosticismo tecnológico", entendido mais como uma inclinação do que como uma corrente designável. Tratarse-iam, aqui, sobretudo de tendências gnosticizantes da pesquisa tecno-cientifica atual, mais evidentes, por exemplo, em certas áreas, como a da genética molecular, desenvolvida a partir dos anos 50, ou, mais recentemente, da engenharia biológica. O trabalho de Hermínio Martins aponta, igualmente, para a urgente necessidade de uma reflexão ética e política, por conta da mudança radical de perspectiva sobre o orgânico, sobre a vida. Indo de encontro a uma tendência pósmoderna avessa a qualquer "profundidade" ontológica ou epistemológica (p. 196), o sociólogo propõe uma "metafisica mais reflexiva e valorativa" que não tome como simplesmente adquiridas as implicações ontológicas e axiológicas das tecnologias contemporâneas (p. 192), sobretudo por não se poder desconhecer os vastos potenciais destrutivos das práticas tecno-econômicas. Eis um trecho revelador de sua posição: 
[...] os tropos da tecnologia merecem um escrutínio metafisico especial em vez de um apoio 2triunfalista ou de uma forte presunção antecedente de adequação metafisica. As nossas estâncias éticas não deveriam ser acriticamente modeladas pelos tropos tecno-cientificos que prevalecem em qualquer periodo particular [...]. (p.193)

No ensaio "Tecnologia, modernidade e política" ao "Hegel, Texas", Hermínio Martins analisa duas tradições divergentes do pensamento ocidental sobre a técnica: a prometéica, ligada ao positivismo, ao socialismo utópico, à Revolução Francesa e ao huma-nismo de matiz socialista; e a fáustica, vinculada ao pensamento alemão, tendo, como ponto culminante, Heidegger. De modo geral, a tradição prometéica traduz uma visão instrumental da técnica e relaciona o domínio técnico da natureza a fins humanos e ao bem da humanidade, enquanto a tradição fáustica critica a visão prometéica e desvincula a técnica de qualquer objetivo humano para além de sua própria expressão. Articulando os dois ensaios do sociólogo, observase a afinidade entre a concepção moderna da técnica e a visão prometéica, e, por outro lado, a inflexão fáustica da tecnociência contemporânea. Daí, inclusive, o interesse e a extrema relevância do segundo ensaio de Hermínio Martins a que nos referimos.

A visão prometéica, que se estende de Auguste Comte, Charles Fourier e Saint-Simon ao marxismo russo, aposta firmemente no aprimoramento tecnológico das condições de vida da espécie, considerando o melhoramento da condição humana como consequiência necessária do domínio tecnológico da natureza. A concepção fáustica, que se expande na Alemanha da República de Weimar e do Terceiro Reich, pressupõe a prioridade ontológica da técnica sobre a ciência, dissociando os procedimentos científicos da busca da verdade ou do conhecimento da natureza íntima das coisas. Nesta perspectiva, a tecnociência visaria, antes, à compreensão do mundo fenomênico apenas para fins de previsão e de controle. $\mathrm{O}$ impulso tecnológico para o domínio do mundo próprio da moderna cultura ocidental desvinculase, para os teóricos fáusticos, da história da racionalidade ocidental, surgindo em total descontinuidade com outras épocas e outras culturas. A técnica não derivaria de uma racionalidade cognitiva anterior, mas manifestaria os valores básicos de determinada cultura. Trata-se, segundo Hermínio Martins, de uma "teoria expressivista da técnica" (p. 234), relacionada a uma ênfase na "expressão" característica do 
pensamento alemão da época. O sociólogo observa, ainda, que houve uma versão nazista da filosofia expressionista da técnica, vinculada a uma noção particularista e racista de cultura, avessa a qualquer conceito universalizante, tal como o de uma racionalidade humana genérica.

O ethos da técnica moderna, na visão fáustica, consistiria no impulso de dominar o mundo, na apropriação de toda a natureza e no controle planetário, e seria totalmente estranho a todas as demais culturas técnicas. Os teóricos fáusticos rejeitavam as abordagens e justificações utilitárias usuais, pois estas pressupõem uma identidade entre culturas necessariamente diversas. Hermínio Martins menciona a espantosa hostilidade desses teóricos contra a idéia comum de que o objetivo ou a principal função da técnica seria aliviar a miserável condição da maioria dos homens (p. 235). Para Heidegger, tanto o americanismo quanto o bolchevismo seriam "metafisicamente idênticos", por postularem o desenvolvimento técnico como um meio eficaz para satisfazer as necessidades da maioria. Delineia-se, assim, a afinidade entre tal concepção da técnica como destino de uma cultura específica, avessa, portanto, a concepções utilitaristas, universalizantes, igualitárias, e governo autoritário. Os ideais e valores igualitários, liberais e democráticos ancoram-se, em última instância, na firme crença em uma racionalidade universal. Desacreditada tal noção e afirmada enfaticamente a peculiaridade de culturas nacionais, abre-se espaço para governos autoritários que supostamente estariam mais aptos a levar tais culturas à sua realização máxima.? . Outra articulação importante, operada pelos teóricos fáusticos, é a da técnica, pensada como impulso para a apropriação ilimitada da natureza, com o capitalismo, com seu impulso para a acumulação igualmente sem fim.

O que subjaz à visão prometéica da técnica, tanto nos moldes do positivismo quanto nos do marxismo clássico é, no final das contas, uma crença irrestrita na racionalidade. No caso da tradição positivista, que se estende de uma maneira mais geral ao pensamento moderno, aposta-se na racionalidade da ciência, no progresso do conhecimento e da técnica, que levaria, necessariamente, à melhoria da precária condição humana. No caso do marxismo clássico, tal crença associa-se à fé na racionalidade da história. Os pensadores fáusticos afastam-se igualmente de ambas as crenças. A hubris prometéica provém, sem dúvida, dessa fé cega nas vantagens da racionalidade - tanto da ciência quanto da história. Tanto a queda do socialismo de Estado quanto os recentes movimentos nervosos do atual capitalismo de base finan- 
ceira parecem abalar, definitivamente, a fé na orientação racional global das sociedades. Mas o projeto faustiano de gestão total dos mundos orgânico e inorgânico (p. 189), entretanto, é cada vez mais favorecido pela tecnociência contemporânea, que permite e intensifica, de modo inédito, a manipulação radical da geosfera e do próprio mundo orgânico. A hubris fáustica ronda, portanto, a agenda da demiurgia tecnológica atual, solicitando a mais cerrada reflexão ético-política, sob pena de não mais resistirmos, como afirma Hermínio Martins no final do seu ensaio, à tirania das possibilidades tecnológicas (p. 245).

\section{Notas}

1 Cf. Hermínio Martins, "Hegel, Texas: temas de filosofia e sociologia da técnica" in Hegel, Texas e outros ensaios de teoria social, Lisboa: Edições Século XXI, 1996. Todas as referências de página remeterão, ao longo do texto, a esta edição.

2 Cf. Idem, ibid, p. 167. Em nossa exposição, estaremos, em algumas 124 passagens, perseguindo de perto o referido ensaio, resumindo suas idéias principais e eliminando, em benefício de maior agilidade do texto, as aspas.

3 Conforme referência do autor, cf. Victor Ferkiss, "Technology and culture: gnosticism, naturalism and incarnational integration", Cross-currents, XXX, 1980.

4 Cf. Paul Virilio, O espaço crítico. Rio de Janeiro: Editora 34, 1993.

5 Citado em Hermínio Martins, op. cit., pp. 181-182.

6 Cf. Idem, ibid, pp. 199-245.

7 A este respeito, Hermínio Martins observa: "Para que a técnica cumpra o seu destino, deve satisfazer preocupações nacionais "autênticas" - tanto a favor da comunidade alemã que representava como contra o ocidente. Heidegger, de maneira notória, nunca haveria de entender o sucesso tecnológico do ocidente democrático durante e após a Segunda Guerra Mundial." (p. 239) 